\title{
Study of the antibacterial and antifungal activities of synthetic benzyl bromides, ketones, and corresponding chalcone derivatives
}

This article was published in the following Dove Press journal:

Drug Design, Development and Therapy

8 November 2016

Number of times this article has been viewed

\author{
Muhamad Ali K Shakhatreh' \\ Mousa L Al-Smadi² \\ Omar F Khabour ${ }^{1,3}$ \\ Fatima A Shuaibu' \\ Emad I Hussein ${ }^{4}$ \\ Karem H Alzoubi ${ }^{5}$ \\ 'Department of Medical Laboratory \\ Sciences, ${ }^{2}$ Department of Applied \\ Chemical Sciences, Jordan University \\ of Science and Technology, Irbid, \\ Jordan; ${ }^{3}$ Faculty of Applied Medical \\ Sciences, Taibah University, Madina, \\ Saudi Arabia; ${ }^{4}$ Department of \\ Biological Sciences, Yarmouk \\ University, ${ }^{5}$ Department of Clinical \\ Pharmacy, Jordan University of \\ Science and Technology, Irbid, Jordan
}

Correspondence: Muhamad Ali K Shakhatreh

Department of Medical Laboratory Sciences, Faculty of Applied Medical Sciences, Jordan University of Science and Technology, Irbid 221 10, Jordan Tel +962 27201000 ext 23874 Email mohdshakatreh@yahoo.com

\begin{abstract}
Several applications of chalcones and their derivatives encouraged researchers to increase their synthesis as an alternative for the treatment of pathogenic bacterial and fungal infections. In the present study, chalcone derivatives were synthesized through cross aldol condensation reaction between 4-( $N, N$-dimethylamino)benzaldehyde and multiarm aromatic ketones. The multiarm aromatic ketones were synthesized through nucleophilic substitution reaction between 4-hydroxy acetophenone and benzyl bromides. The benzyl bromides, multiarm aromatic ketones, and corresponding chalcone derivatives were evaluated for their activities against eleven clinical pathogenic Gram-positive, Gram-negative bacteria, and three pathogenic fungi by the disk diffusion method. The minimum inhibitory concentration was determined by the microbroth dilution technique. The results of the present study demonstrated that benzyl bromide derivatives have strong antibacterial and antifungal properties as compared to synthetic chalcone derivatives and ketones. Benzyl bromides (1a and 1c) showed high ester activity against Gram-positive bacteria and fungi but moderate activity against Gram-negative bacteria. Therefore, these compounds may be considered as good antibacterial and antifungal drug discovery. However, substituted ketones $(2 \mathrm{a}-\mathrm{b})$ as well as chalcone derivatives $(3 \mathrm{a}-\mathrm{c})$ showed no activity against all the tested strains except for ketone (2c), which showed moderate activity against Candida albicans.
\end{abstract}

Keywords: benzyl bromides, ketones, chalcone derivatives, antibacterial activity, antifungal activity

\section{Introduction}

Chalcones are open-chain flavonoids with two aromatic rings joined by a three-carbon $\alpha, \beta$-unsaturated carbonyl system (Figure 1). They are found abundantly in fruits and vegetables. ${ }^{1}$ Chalcones are used as precursors in the biosynthesis of flavonoids and isoflavonoids. Some of them were found to have remarkable biological activities and can act as antibacterial, ${ }^{2}$ antifungal, ${ }^{3}$ antiinflammatory, ${ }^{4}$ antimalarial, ${ }^{5}$ and anticancer agents. ${ }^{6}$ The presence of $\alpha, \beta$-unsaturated carbonyl moiety as the functional group makes the chalcones biologically active. ${ }^{7}$ Chalcones are used as intermediates in the synthesis of various heterocyclic compounds such as pyrazoles, which are used as anticancer, antiinflammatory, antitumor, antibacterial, antipyretic, antidiabetic, and anticonvulsant agents and as monoamine oxidase inhibitors. ${ }^{8-11}$

Chalcones are found as dimmers, oligomers, and conjugates of different kinds. Additionally, various groups of hydroxyl, methoxy, and alkenyl functionalities can be attached to the framework of chalcone and contribute to its structural diversity. ${ }^{12,13}$ They are found as yellow pigments in flowers, roots, and leaves of species of genera Angelica, Artocarpus, and Dorstenia and widely distributed in fruits, vegetables, spices, tea, and 


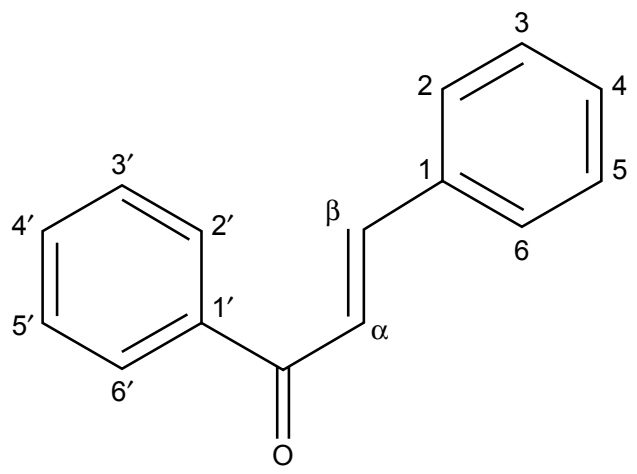

Figure I General structure of chalcone.

beer. ${ }^{14}$ Increase in resistance to antimicrobial agents has been a major concern for public health over the last few decades. Thus, the need for new drugs/compounds for the new disease and resistant strains is an essential part of medical care.

Several studies have shown that the introduction of different functional groups can improve the biological activity of chalcones. Regarding the antifungal activities of chalcones, the emergence of resistant strains of Candida species due to the intensive use of antifungal drugs increased the interest to develop new therapeutics. ${ }^{15}$ The antifungal activity of chalcone is due to its effect on the cell wall, which depends largely on its potential to interact with sulfhydryl groups. ${ }^{16}$

The present study examined the antibacterial and antifungal activities of prepared benzyl bromides $(1 \mathrm{a}-\mathrm{c})$, substituted ketones $(2 \mathrm{a}-\mathrm{c})$, and substituted chalcone derivatives $(3 \mathrm{a}-\mathrm{c})$ against selected clinical pathogenic strains of bacteria and fungi. Chalcone derivatives $(3 \mathrm{a}-\mathrm{c})$ were synthesized through cross aldol condensation reaction between aromatic ketones (2a-c) and 4-( $N, N$-dimethylamino)benzaldehyde in basic medium (Figure 2). The procedure of synthesis, structures of various compounds, elemental analyses, nuclear magnetic resonance $\left({ }^{1} \mathrm{H}\right.$ - and ${ }^{13} \mathrm{C}$-nuclear magnetic resonance), infrared, and mass spectral data of all compounds were previously published by Al-Smadi and Al-Momani. ${ }^{17}$

\section{Materials and methods} Synthesized compounds

All synthesized compounds including benzyl bromides $(1 \mathrm{a}-\mathrm{c})$, ketones $(2 \mathrm{a}-\mathrm{c})$ and chalcone derivatives $(3 \mathrm{a}-\mathrm{c})$ were obtained from Al-Smadi and Al-Momani. ${ }^{17}$ The multiarm chalcone derivatives $(3 \mathrm{a}-\mathrm{c})$ were synthesized (prepared) in basic medium by cross aldol condensation reaction between ketones (2a-c) and 4-(N,N-dimethylamino) benzaldehyde. ${ }^{17}$

\section{Test microorganisms}

As shown in Table 1, a total of 14 reference clinical bacterial and fungal strains were obtained from King Abdullah University
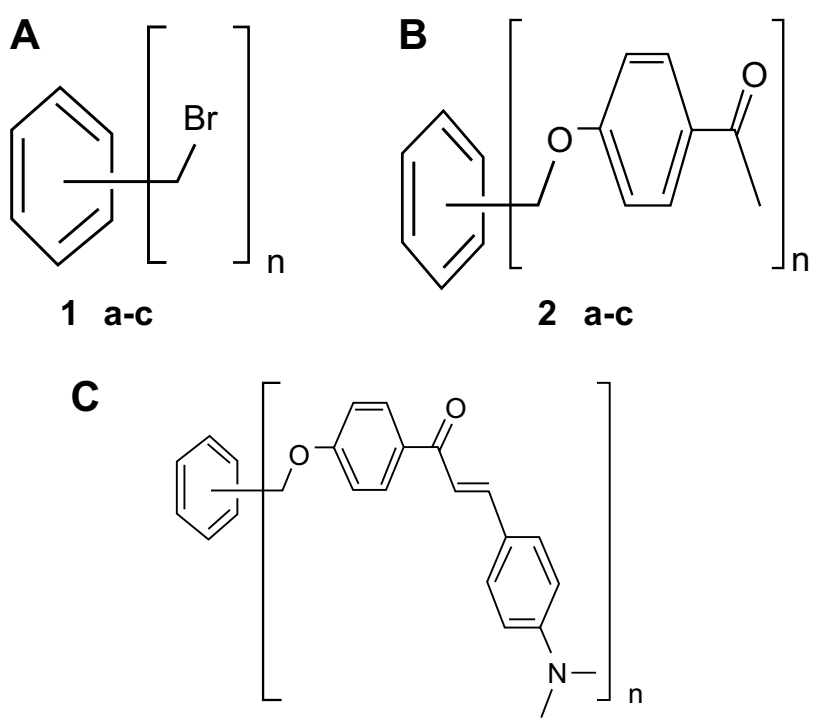

3 a-c

Figure 2 Synthesized chalcones used in the present study; benzyl bromides ( $\mathrm{la}-\mathrm{c})$, substituted ketones $(2 a-c)$, and substituted chalcone derivatives $(3 a-c)$, where $A$ : $n=2, B: n=3, C: n=4$.

Hospital (KAUH) diagnostic laboratories. The pathogenic bacterial strains were Staphylococcus aureus, Pseudomonas aeruginosa, Enterococcus faecalis, Escherichia coli, Shigella dysenteriae, Salmonella typhi, Streptococcus pyogenes, Citrobacter freundii, Enterobacter aerogenes, Klebsiella pneumoniae, and Acinetobacter species. The pathogenic fungal strains were Candida albicans, Candida krusei ATCC14243, and Aspergillus niger ATCC16404. Antibacterial and antifungal activities were evaluated by the disk diffusion and the microbroth dilution methods as recommended by the Clinical and Laboratory Standards Institute (CLSI) ${ }^{18-20}$ and the European Committee on Antimicrobial Susceptibility Testing (EUCAST). ${ }^{21,22}$ As bacterial samples were obtained from the pathology laboratory stored samples, and were not identified to a certain patient, the Institutional Review Board of Jordan University of Science and Technology does not require ethics approval to be obtained.

Table I Pathogenic bacteria and fungi used for the antimicrobial assays

\begin{tabular}{ll}
\hline Bacterial strain & Fungal strain \\
\hline Staphylococcus aureus & Candida albicans \\
Enterococcus faecalis & Candida krusei \\
Streptococcus pyogenes & Aspergillus niger \\
Pseudomonas aeruginosa & \\
Escherichia coli & \\
Shigella dysenteriae & \\
Salmonella typhi & \\
Citrobacter freundii & \\
Enterobacter aerogenes & \\
Klebsiella pneumoniae & \\
Acinetobacter species &
\end{tabular}




\section{Antibacterial activity of the synthetic compounds using disk diffusion \\ Preparation of synthetic compounds for microbiological assay}

A stock solution of $10 \mathrm{mg}$ of each synthetic compound dissolved in $1 \mathrm{~mL}$ of dimethyl sulfoxide (DMSO) as solvent was prepared. The antimicrobial activity of the synthesized compounds was evaluated by the disk diffusion method and the microbroth dilution method, which determines minimum inhibitory concentration (MIC). ${ }^{23}$

\section{Determination of antibacterial activity by disk diffusion method}

Antibacterial activity of the prepared synthetic compounds against the Gram-negative and the Gram-positive bacterial strains were examined by disk diffusion assay. Bacterial cultures were obtained from KAUH diagnostic laboratories. Isolated pure colonies from fresh grown bacteria were transferred from the plates into sterile normal saline solution and vortexed to form bacterial homogenous suspensions. The turbidity was then adjusted to $0.5 \mathrm{McF}$ arland standard units, and the suspensions were poured over Mueller-Hinton agar (MHA) plates. Sterile filter paper disks with a diameter of $6 \mathrm{~mm}$ were placed over these plates. The sterile disks were impregnated with $20 \mu \mathrm{L}$ of the tested compounds $(10 \mathrm{mg} / \mathrm{mL}$ dissolved in DMSO). Positive control (Amoxicillin) and negative control (sterile distilled water) were used. Finally, the plates were incubated at $37^{\circ} \mathrm{C}$ for 24 hours. The inhibition zones were measured in millimeter. ${ }^{24}$

\section{Antifungal disk diffusion method}

The fungal strains were cultured on Sabouraud dextrose agar and incubated at $35^{\circ} \mathrm{C}$ for 24 hours and for 5 days on potato dextrose agar slant for the mold fungi. Using a sterile loop, pure colonies of the Candida species were transferred into a tube containing sterile normal saline. For the mold, $1 \mathrm{~mL}$ of sterile distilled water supplemented with $0.1 \%$ Tween 20 was used to cover and resuspend the colonies. Using a hemocytometer, the suspension was adjusted to $2-5 \times 10^{6}$ conidia/mL. The suspension was further diluted 1:10 to obtain final working inoculums $2-5 \times 10^{5}$ conidia $/ \mathrm{mL}$. The inoculums were poured over MHA supplemented with $2 \%$ of glucose. The sterile $6 \mathrm{~mm}$ disks that were impregnated with $20 \mu \mathrm{L}$ test compound (with a concentration of $10 \mathrm{mg} / \mathrm{mL}$ ) were placed over the plate.

Standard antifungal drug Nystatin was used as positive control and sterile distilled water as negative control and incubated at $35^{\circ} \mathrm{C}$ for 48 hours. The zone of inhibition was measured in millimeter. ${ }^{23}$

\section{MICs by microbroth dilution method}

The MIC was determined by measuring the absorbance of microtiter plates at $570 \mathrm{~nm}$ for bacteria and $530 \mathrm{~nm}$ for fungi. While for $A$. niger, MIC was determined visually. The optical density from each well was compared with optical density from the positive control wells, the lowest concentration with optical density $<0.1$ signifies inhibition and considered as MIC.

\section{Antibacterial susceptibility testing by microbroth dilution method}

The pure bacterial culture of each microorganism was adjusted to 0.5 McFarland standards in Mueller-Hinton broth (MHB). The bacterial inoculums were vortexed and diluted in MHB. The bacterial suspension was used within 30 minutes after turbidity adjustment to avoid duplication of the bacterial cells. Eight different concentrations were prepared from each stock with the medium $(0.125,0.25,0.5$, $1,2,4,6$, and $8 \mathrm{mg} / \mathrm{mL}$ ). A total of $50 \mu \mathrm{L}$ of each compound concentration was added to sterile 96 -well microtiter plates. After that, $50 \mu \mathrm{L}$ of diluted bacterial inoculums were added to each well including the negative control lane, and $100 \mu \mathrm{L}$ of broth was added to positive control lane. (Each well reached the final desired concentration of $5 \times 10^{5} \mathrm{CFU} / \mathrm{mL}$.) The plates were then incubated at $37^{\circ} \mathrm{C}$ for $18-24$ hours. Then, they were examined to check where growth had taken place, and the inhibition of growth was determined by measuring the absorbance at $570 \mathrm{~nm}$ using an enzyme-linked immunosorbent assay (ELISA) reader. ${ }^{24}$

\section{Antifungal susceptibility testing by microbroth dilution method}

The MICs for C. albicans and C. krusei were determined using the reference procedure of the Antifungal Susceptibility Testing of CLSI M27-A $3^{19}$ and EUCAST for the testing of fermentative yeasts. ${ }^{22}$ MICs for A. niger (mold) were determined in accordance with EUCAST ${ }^{22}$ and CLSI M38-A. ${ }^{20}$ Briefly, testing was performed in sterile 96-well microtiter plates with Roswell Park Memorial Institute (RPMI) 1640 medium with L-glutamine, without sodium bicarbonate $\left(\mathrm{NaHCO}_{3}\right.$, RPMI 1640; Gibco, Carlsbad, CA, USA) supplemented with $2 \%$ glucose, buffered to $\mathrm{pH} 7.0$ with 4-(2-hydroxyethyl)-1-piperazineethanesulfonic acid (HEPES) medium.

\section{Preparation of fungal (yeasts and molds) inoculums}

Regarding preparation of yeast inoculums, the fungal strains were subcultured on Sabouraud's dextrose agar slant and 
incubated for $24-48$ hours at $35^{\circ} \mathrm{C}$ to obtain a freshly grown pure culture. Homogenous suspension was adjusted to 0.5 McFarland standards. Then, the inoculum size was further adjusted to $0.5 \times 10^{5}$ or $2.5 \times 10^{5}$. In addition, regarding the preparation of mold inoculums, the mold suspension of conidia was obtained from 5 days culture Sabor and dextrose agar slant incubated at $35^{\circ} \mathrm{C}$. Colonies were covered with $5 \mathrm{~mL}$ of sterile distilled water supplemented with Tween 20. The conidia were collected with a sterile cotton swab, transferred to a sterile tube, and vortexed to homogenize the suspension. The suspension was standardized by counting the conidia in a hemocytometer to $2-5 \times 10^{6}$ conidia $/ \mathrm{mL}$. The suspension was diluted 1:10 with RPMI to obtain final inoculums of $2-5 \times 10^{5}$ conidia $/ \mathrm{mL}$. A total of $50 \mu \mathrm{L}$ of each compound concentration and $50 \mu \mathrm{L}$ of fungal suspension were added to each well for the negative control lane, but $100 \mu \mathrm{L}$ of broth was added to the positive control lane (each well reached the final desired concentration of $2-5 \times 10^{5} \mathrm{CFU} / \mathrm{mL}$ ). The plate was sealed with aluminum foil and incubated at $35^{\circ} \mathrm{C}$ for 2,448 hours in humid atmosphere. The MIC was determined using an ELISA reader at $530 \mathrm{~nm}$ for the yeast species and visually for mold species after 48 hours of incubation as the lowest concentration of drug that resulted in $50 \%$ inhibition of growth compared to that drug-free growth control. ${ }^{18-20}$

\section{Results}

\section{Antibacterial and antifungal susceptibility testing}

The benzyl bromides $(1 \mathrm{a}-\mathrm{c})$, ketones $(2 \mathrm{a}-\mathrm{c})$, and chalcone derivatives $(3 \mathrm{a}-\mathrm{c})$ were tested against eleven clinical pathogenic strains of bacteria and three pathogenic fungal strains. The methods include the disk diffusion method and broth microdilution method for MIC determination in accordance with CLSI and EUCAST. ${ }^{18-22}$

As shown in Tables 2 and 3, the antibacterial and antifungal activities of the nine synthetic derivatives (benzyl bromide derivatives [1a-c], ketones [2a-c], and chalcone derivatives [3a-c]) were tested against clinical pathogenic bacterial and fungal strains. The benzyl bromide derivatives were the most effective compounds against the following Grampositive bacteria: S. aureus, S. pyogenes, and E. faecalis with a range of inhibition zones (10-17 mm). Benzyl bromide derivative (1a) showed moderate effect against the Gramnegative bacteria E. coli, C. freundii, K. pneumoniae, and S. typhi with an inhibition zone of $7 \mathrm{~mm}$. Benzyl bromide derivatives (1b) and (1c) showed moderate antibacterial activity against the tested Gram-positive bacteria $S$. aureus and $E$. faecalis with a range of inhibition zones $(8-9 \mathrm{~mm})$.

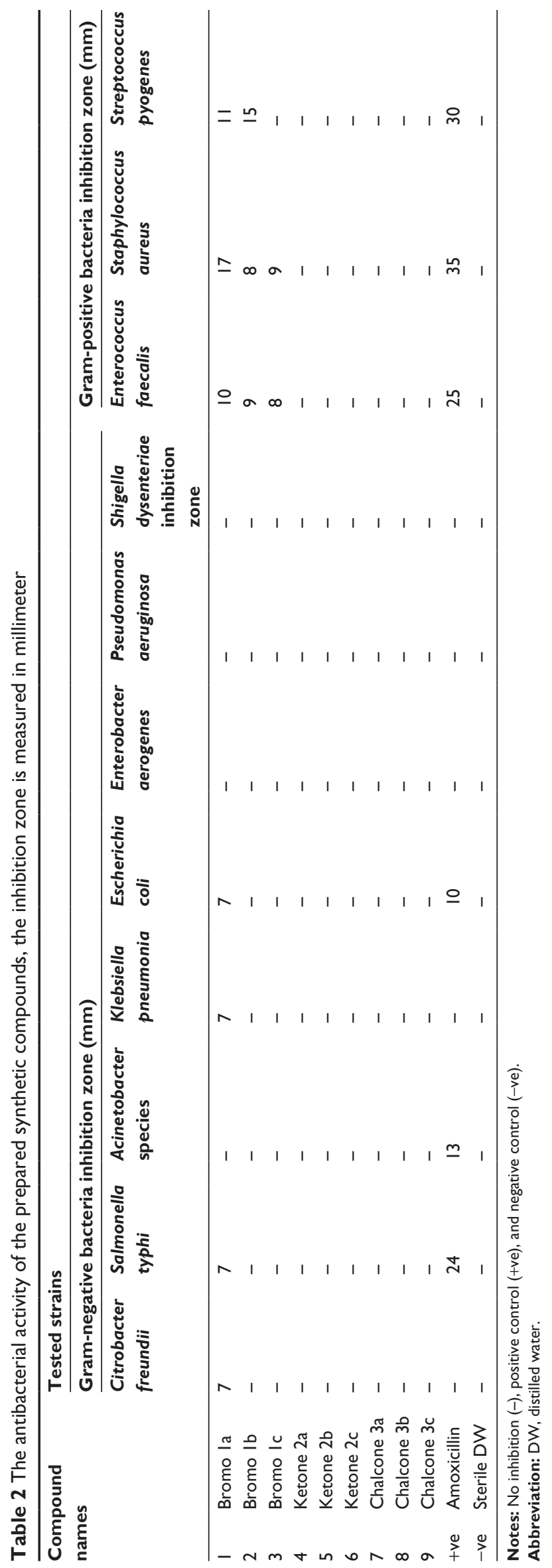


Table 3 The antifungal activity of the nine prepared synthetic compounds, the inhibition zone is measured in millimeter

\begin{tabular}{lllll}
\hline Compound names & \multicolumn{3}{c}{ Tested pathogenic fungal strains } \\
\cline { 3 - 5 } & & $\begin{array}{l}\text { Candida } \\
\text { albicans }\end{array}$ & $\begin{array}{l}\text { Candida } \\
\text { krusei }\end{array}$ & $\begin{array}{l}\text { Aspergillus } \\
\text { niger }\end{array}$ \\
\hline I & Bromo Ia & 35 & 20 & 14 \\
2 & Bromo Ib & 9 & 10 & - \\
3 & Bromo Ic & 10 & 10 & - \\
4 & Ketone 2a & - & - & - \\
5 & Ketone 2b & - & - & - \\
6 & Ketone 2c & 7 & - & - \\
7 & Chalcone 3a & - & - & - \\
8 & Chalcone 3b & - & - & - \\
9 & Chalcone 3c & - & - & - \\
$+\mathrm{ve}$ & Amoxicillin & $\mathrm{I}$ & $\mathrm{I}$ & $\mathrm{I}$ \\
$-\mathrm{ve}$ & Sterile DW & - & - & - \\
\hline
\end{tabular}

Notes: No inhibition (-), positive control (+ve), and negative control (-ve). Abbreviation: DW, distilled water.

Benzyl bromide derivative (1b) was highly active against S. pyogenes, with an inhibition zone of $15 \mathrm{~mm}$. In addition, the benzyl bromide derivatives showed no activity against the tested Gram-negative bacteria as shown in Table 2. Benzyl bromide derivatives $(1 \mathrm{a}-\mathrm{c})$ were highly effective against both C. albicans and C. krusei and showed inhibition zones ranging from 9 to $35 \mathrm{~mm}$. Furthermore, benzyl bromide derivative (1a) was the only highly effective compound against $A$. niger with an inhibition zone of $14 \mathrm{~mm}$. Ketone (2c) had a moderate effect against $C$. albicans with an inhibition zone of $7 \mathrm{~mm}$ as shown in Table 3. On the other hand, substituted chalcone derivatives $(3 a-c)$ as well as ketones $(2 a-b)$ showed no activity against all the tested pathogenic bacterial and fungal strains except for ketone (2c), which showed moderate activity against $C$. albicans with an inhibition zone of $7 \mathrm{~mm}$.

\section{MIC determination}

The antimicrobial potential of the synthesized compounds was evaluated (assessed) by determining the MIC values by the microdilution method. The MICs were determined by measuring the absorbance of microtiter plates at $570 \mathrm{~nm}$ for bacteria and $530 \mathrm{~nm}$ for fungi (yeasts). For A. niger, MICs were determined visually. The optical density from each well was compared with optical density from the positive control wells, the lowest concentration with optical density $<0.1$ signifies inhibition and considered as our MIC value (Tables 4 and 5). Benzyl bromides (1a) and (1c) were the most effective synthetic compounds having the least MIC value with widest spectrum of antibacterial activity as compared to the other tested compounds. The MIC value for benzyl bromide (1a) was $1 \mathrm{mg} / \mathrm{mL}$ against $S$. aureus and
Table 4 The MIC values of benzyl bromides against pathogenic bacterial strains

\begin{tabular}{llll}
\hline $\begin{array}{l}\text { Gram-positive } \\
\text { bacteria }\end{array}$ & $\begin{array}{l}\text { Bromo Ia, } \\
\text { MIC } \\
\mathbf{( m g / m L})\end{array}$ & $\begin{array}{l}\text { Bromo Ib, } \\
\mathbf{M I C} \\
\mathbf{( m g / m L})\end{array}$ & $\begin{array}{l}\text { Bromo Ic, } \\
\mathbf{M I C} \\
\mathbf{( m g / m L}\end{array}$ \\
\hline Streptococcus pyogenes & 2 & - & 0.5 \\
Staphylococcus aureus & $\mathrm{I}$ & - & 4 \\
Enterococcus faecalis & 2 & - & 2 \\
Gram-negative bacteria & & & \\
$\quad$ Klebsiella pneumoniae & 2 & - & 4 \\
Acinetobacter spp. & - & - & - \\
Enterobacter aerogenes & - & - & - \\
Salmonella typhi & 2 & - & 4 \\
Shigella dysenteriae & - & - & - \\
Escherichia coli & 2 & - & 2 \\
Citrobacter freundii & 2.5 & - & 4 \\
Pseudomonas & - & - & - \\
aeruginosa & & & \\
\hline
\end{tabular}

Note: Not detected (-).

Abbreviation: MIC, minimum inhibitory concentration.

$2 \mathrm{mg} / \mathrm{mL}$ against $S$. pyogenes, E. faecalis, $K$. pneumoniae, $S$. typhi, and E. coli. The MIC value for benzyl bromide (1c) was $0.5 \mathrm{mg} / \mathrm{mL}$ against $S$. pyogenes, $2 \mathrm{mg} / \mathrm{mL}$ against E. faecalis, and $4 \mathrm{mg} / \mathrm{mL}$ for $S$. aureus, K. pneumoniae, and S. typhi. In addition, benzyl bromide (1b) showed poor and nondetectable antimicrobial activity against both Gramnegative and Gram-positive bacteria. Regarding MIC for pathogenic fungi, benzyl bromide (1a) had the lowest MIC with $0.25 \mathrm{mg} / \mathrm{mL}$ as the most effective compound against C. albicans. The lowest MIC value obtained for benzyl bromide (1c) was against C. krusei $(0.5 \mathrm{mg} / \mathrm{mL})$.

\section{Discussion}

In the present study, the antibacterial and antifungal activities of nine synthesized compounds including the benzyl bromides $(1 \mathrm{a}-\mathrm{c})$, ketones $(2 \mathrm{a}-\mathrm{c})$, and chalcone derivatives $(3 a-c)$ were evaluated and tested against different pathogenic bacterial strains and fungal strains. The obtained results showed that benzyl bromides have strong antibacterial and antifungal properties as compared to the corresponding ketones and chalcone derivatives. The antimicrobial activity measurements of the nine tested synthetic compounds

Table 5 The MIC values of benzyl bromides against pathogenic fungal strains

\begin{tabular}{lllll}
\hline Fungi & $\begin{array}{l}\text { Bromo Ia } \\
(\mathbf{m g} / \mathbf{m L})\end{array}$ & $\begin{array}{l}\text { Bromo Ib } \\
(\mathbf{m g} / \mathbf{m L})\end{array}$ & $\begin{array}{l}\text { Bromo Ic } \\
(\mathbf{m g} / \mathbf{m L})\end{array}$ & $\begin{array}{l}\text { Ketone 2c } \\
(\mathrm{mg} / \mathbf{m L})\end{array}$ \\
\hline Candida albicans & 0.25 & - & $\mathrm{I}$ & - \\
Candida krusei & $\mathrm{I}$ & - & 0.5 & - \\
Aspergillus niger & $\mathrm{I}$ & - & - & - \\
\hline
\end{tabular}

Note: Not detected: (-).

Abbreviation: MIC, minimum inhibitory concentration. 
were performed by the disk diffusion method. All synthetic derivatives proved themselves to be more active against Gram-positive bacteria than Gram-negative. Benzyl bromide (1a) was the most active compound (highly effective) against Gram-positive cocci including $S$. aureus, S. pyogenes, and E. faecalis. Additionally, benzyl bromide (1a) has a moderate antimicrobial effect against the Gram-negative bacteria: E. coli, C. freundii, K. pneumoniae, and S. typhi. Furthermore, benzyl bromides (1b) and (1c) showed a moderate to high antibacterial activity against the tested Gram-positive bacteria $S$. aureus, E. faecalis, and $S$. pyogenes. The mechanism of bactericidal action is thought to be due to disruption of intermolecular interactions. This can cause dissociation of cellular membrane lipid bilayers, which compromises cellular permeability controls and induces leakage of cellular contents. The chalcones structure-activity relationship potency against $C$. albicans depends to a large extent on their ability to interact with thiol and hydroxyl chalcones. ${ }^{15}$ Furthermore, the location of the hydroxyl group is strongly involved, the ortho-position and not the para- or the meta-being the most favorable, because of a mechanism by which the $o$-hydroxyl groups are involved in intermolecular hydrogen bond formation facilitating the addition of thiols. ${ }^{25}$ Strong antifungal effects were obtained for the compounds of the series against dermatophytes, a group of fungi that infect the keratinized areas of the body. Regarding the influence of the substituents on the $\mathrm{B}$ ring, an interesting structure-activity correlation could be observed: electron-donating groups tended to weaken the antifungal activity while electron-withdrawing groups in the para-position increased the potency so that a nitro substituent enhanced the activities and an $-\mathrm{N}\left(\mathrm{CH}_{3}\right)_{2}$ had almost the lowest activity. ${ }^{26}$ Therefore, it would be interesting to try a withdrawing group such as $\mathrm{NO}_{2}$ or $\mathrm{CN}$ or a halogen in the para rather than $-\mathrm{N}\left(\mathrm{CH}_{3}\right)_{2}$.

The antifungal activity measurements of the nine tested synthetic compounds were performed by the disk diffusion method. Benzyl bromides (1a), (1b), and (1c) were all active (highly effective) against both pathogenic fungi: C. albicans and C. krusei. Additionally, benzyl bromide (1a) was found to be distinguished among the nine tested compounds and showed to be highly active against the pathogenic fungus A. niger. Regarding ketones, ketone (2c) was found to have moderate antifungal effect against $C$. albicans. The chalcone derivatives $(3 a-c)$ as well as ketones $(2 a-b)$ showed no antibacterial or antifungal activity against all the tested pathogenic bacterial and fungal strains.

Furthermore, in order to evaluate the antimicrobial activity of the tested compounds in the present study; the MIC which is the lowest concentration of the tested compound that produced no visible bacterial growth (no turbidity) when compared with the control was determined by the microdilution method. Benzyl bromides (1a) and (1c) gave the least (MIC) values against Gram-positive cocci strains: S. aureus, S. pyogenes, E. faecalis, K. pneumoniae, S. typhi, and $E$. coli and proved themselves to be the most active of the nine compounds. Benzyl bromide (1b) showed poor and nondetectable antibacterial activity against both Grampositive and Gram-negative bacteria. Regarding (MIC) pathogenic fungi, benzyl bromide (1a) was found to be the most active (effective) compound against $C$. albicans. The results obtained showed that the tested chalcone derivatives that contain aromatic amine substituents have no antibacterial or antifungal activity against all the tested clinical pathogenic species of bacteria and fungi. Many chalcones are known to exhibit reasonable antimicrobial and antifungal activity due to the presence of $\alpha, \beta$-unsaturated carbonyl groups that can enhance the activity. ${ }^{3,4}$ In case of chalcone derivatives $(3 \mathrm{a}-\mathrm{c})$, there are more than one $\alpha, \beta$-unsaturated carbonyl group (chalcone) substituted on one benzene ring, which leads to electronic and steric interactions between the substituents. In addition to the large size of the substituents, the presence of an electron donating group ( $N, N$-dimethyl amine) on the para-position of the chalcone that increases the direct resonance conjugation between the amino group and the chalcone might be the reason for the low antimicrobial and antifungal activity of the chalcone derivatives $(3 a-c)$. The presence of small substituents containing an electron withdrawing group (bromo group) that is surrounded by high electron density might be the reason for the high antibacterial and antifungal activity of the benzyl bromides $(1 \mathrm{a}-\mathrm{c})$. Therefore, the inactivity of chalcone derivatives $(3 a-c)$ observed in the present study can be due to the presence of variations in compound structure and mode of substitution. Future research may need to be done to investigate antifungal and other biological activities such as antioxidant, antiinflammatory, and anticancer activity of the chalcone derivatives $(3 a-c)$.

Many studies have shown that chalcone derivatives exhibit several significant biological (antibacterial and antifungal) activities with the aim to discover the therapeutic values of them. A series of chalcones containing thiophene aromatic ring instead of benzene were synthesized and showed significant antimicrobial activity. ${ }^{27,28}$ Heterocyclic chalcone derivatives were also prepared and showed moderate activity against methicillin-sensitive $S$. aureus and methicillin-resistant Staphylococcus and no activity against 
vancomycin-resistant $S$. aureus as reported by Tran et al. ${ }^{29}$ The antifungal activity of some chalcones against a dermatophytic fungus was investigated and showed that the presence of electron-donating substituents makes chalcone a weak antifungal agent, while electron-withdrawing substituents in the para position increase the antifungal activity. ${ }^{26}$ Other studies reported that chalcones substituted with thiazole ring showed good antimicrobial activity. ${ }^{30}$ Chalcones with a hybrid of rhodanine-3-acetic acid were reported to possess a potent antimicrobial activity. ${ }^{31}$ Furthermore, a series of quinolinyl chalcones were tested for their in vitro antibacterial activities against different strains of Gram-negative and Gram-positive bacteria and showed significant antimicrobial activity. ${ }^{32}$ Pyrazolyl-substituted chalcone derivatives exhibited strong antimicrobial activities. ${ }^{33}$

\section{Conclusion}

The present study has clinical application as it will establish antimicrobial and antifungal behavior of some synthetic derivatives, which will be basic for future research on developing alternative antibiotics focusing on the development of better antibiotics against infectious organisms. The obtained results indicate that the benzyl bromides $(1 \mathrm{a}-\mathrm{c})$ may have a considerable potential for therapeutic application as a novel drug candidate against bacterial and fungal infections. Depending on the obtained results, some of the studied compounds have proved themselves to be promising candidates for additional efficacy evaluation.

\section{Disclosure}

The authors report no conflicts of interest in this work.

\section{References}

1. Di Carlo G, Mascolo N, Izzo AA, Capasso F. Flavonoids: old and new aspects of a class of natural therapeutic drugs. Life Sci. 1999;65(4): 337-353.

2. Bandgar BP, Gawande SS, Bodade RG, Gawande NM, Khobragade CN. Synthesis and biological evaluation of a novel series of pyrazole chalcones as anti-inflammatory, antioxidant and antimicrobial agents. Bioorg Med Chem. 2009;17(24):8168-8173.

3. Gupta D, Jain DK. Chalcone derivatives as potential antifungal agents: synthesis, and antifungal activity. J Adv Pharm Technol Res. 2015;6(3): 114-117.

4. Bandgar BP, Patil SA, Gacche RN, et al. Synthesis and biological evaluation of nitrogen-containing chalcones as possible anti-inflammatory and antioxidant agents. Bioorg Med Chem Lett. 2010;20(2): 730-733.

5. Yadav N, Dixit SK, Bhattacharya A, et al. Antimalarial activity of newly synthesized chalcone derivatives in vitro. Chem Biol Drug Des. 2012;80(2):340-347.

6. Bandgar BP, Gawande SS. Synthesis and biological screening of a combinatorial library of beta-chlorovinyl chalcones as anticancer, anti-inflammatory and antimicrobial agents. Bioorg Med Chem. 2010; 18(5):2060-2065.
7. Suwito H, Jumina, Mustofa, Kristanti A, Puspaningsih NN. Chalcones: synthesis, structure diversity and pharmacological aspects. J Chem Pharmaceut Res. 2014;6(5):1076-1088.

8. Hsieh HK, Lee TH, Wang JP, Wang JJ, Lin CN. Synthesis and antiinflammatory effect of chalcones and related compounds. Pharm Res. 1998;15(1):39-46.

9. Ramalingam K, Thyvelikakath GX, Berlin KD, et al. Synthesis and biological activity of some derivatives of thiochroman-4-one and tetrahydrothiapyran-4-one. J Med Chem. 1977;20(6):847-850.

10. Ulusoy N. Synthesis and antituberculosis activity of cycloalkylidenehydrazide and 4-aza-1-thiaspiro[4.5]decan-3-one derivatives of imidazo[2,1-b]thiazole. Arzneimittelforschung. 2002;52(7):565-571.

11. Chimenti F, Carradori S, Secci D, et al. Synthesis and inhibitory activity against human monoamine oxidase of N1-thiocarbamoyl-3,5di(hetero)aryl-4,5-dihydro-(1H)-pyrazole derivatives. Eur J Med Chem. 2010;45(2):800-804.

12. Al-Smadi M, Al-Momani F. Synthesis, characterization and antimicrobial activity of new 1,2,3-selenadiazoles. Molecules. 2008;13(11): 2740-2749.

13. Zhang EH, Wang RF, Guo SZ, Liu B. An update on antitumor activity of naturally occurring chalcones. Evid Based Complement Alternat Med. 2013;2013:815621.

14. Nowakowska Z. A review of anti-infective and anti-inflammatory chalcones. Eur J Med Chem. 2007;42(2):125-137.

15. Batovska D, Parushev S, Slavova A, et al. Study on the substituents' effects of a series of synthetic chalcones against the yeast Candida albicans. Eur J Med Chem. 2007;42(1):87-92.

16. Boeck P, Leal PC, Yunes RA, et al. Antifungal activity and studies on mode of action of novel xanthoxyline-derived chalcones. Arch Pharm (Weinheim). 2005;338(2-3):87-95.

17. Al-Smadi M, Mohammad S. Synthesis, characterization, and reactions of selected multichalcone derivatives. J Heterocyclic Chem. 2009;46(2):201-206.

18. Subcommittee on Antifungal Susceptibility Testing (AFST) of the ESCMID European Committee for Antimicrobial Susceptibility Testing (EUCAST). Method for the determination of Broth dilution MICs of antifungal agents for fermentative yeasts. Clin Microbiol Infect Diseases. 2008;14(4):398-405.

19. CLSI. Reference Method for Broth Dilution Antifungal Susceptibility Testing of Yeasts; Approved Standard-Third Edition; CLSI Document M27-A3. Wayne, PA: Clinical and Laboratory Standards Institute; 2008.

20. CLSI. Reference Method for Broth Dilution Antifungal Susceptibility Testing of Filamentous Fungi; Approved Standard CLSI Document M38-A2. Wayne, PA: Clinical and Laboratory Standards Institute; 2008.

21. Chryssanthou E, Cuenca-Estrella M. Comparison of the EUCAST-AFST broth dilution method with the CLSI reference broth dilution method (M38-A) for susceptibility testing of posaconazole and voriconazole against Aspergillus spp. Clin Microbiol Infect. 2006;12(9):901-904.

22. Cuenca-Estrella M, Moore CB, Barchiesi F, et al. Multicenter evaluation of the reproducibility of the proposed antifungal susceptibility testing method for fermentative yeasts of the Antifungal Susceptibility Testing Subcommittee of the European Committee on Antimicrobial Susceptibility Testing (AFST-EUCAST). Clin Microbiol Infect. 2003; 9(6):467-474.

23. Esmadi FT, Khabour OF, Albarqawi AI, Ababneh M, Al-Talib M. Synthesis and characterization of some transition metal complexes of thiocarbohydrazone Schiff bases. Jordan J Chem. 2013;8(1):31-43.

24. Wiegand I, Hilpert K, Hancock RE. Agar and broth dilution methods to determine the minimal inhibitory concentration (MIC) of antimicrobial substances. Nat Protoc. 2008;3(2):163-175.

25. Dinkova-Kostova AT, Massiah MA, Bozak RE, Hicks RJ, Talalay P. Potency of Michael reaction acceptors as inducers of enzymes that protect against carcinogenesis depends on their reactivity with sulfhydryl groups. Proc Natl Acad Sci U S A. 2001;98(6):3404-3409. 
26. Lopez SN, Castelli MV, Zacchino SA, et al. In vitro antifungal evaluation and structure-activity relationships of a new series of chalcone derivatives and synthetic analogues, with inhibitory properties against polymers of the fungal cell wall. Bioorg Med Chem. 2001;9(8): 1999-2013.

27. Bag S, Ghosh S, Tulsan R, et al. Design, synthesis and biological activity of multifunctional alpha,beta-unsaturated carbonyl scaffolds for Alzheimer's disease. Bioorg Med Chem Lett. 2013;23(9):2614-2618.

28. Yin BT, Yan CY, Peng XM, et al. Synthesis and biological evaluation of alpha-triazolyl chalcones as a new type of potential antimicrobial agents and their interaction with calf thymus DNA and human serum albumin. Eur J Med Chem. 2014;71:148-159.

29. Tran TD, Nguyen TT, Do TH, Huynh TN, Tran CD, Thai KM. Synthesis and antibacterial activity of some heterocyclic chalcone analogues alone and in combination with antibiotics. Molecules. 2012; 17(6):6684-6696.
30. Liaras K, Geronikaki A, Glamoclija J, Ciric A, Sokovic M. Thiazolebased chalcones as potent antimicrobial agents. Synthesis and biological evaluation. Bioorg Med Chem. 2011;19(10):3135-3140.

31. Chen ZH, Zheng CJ, Sun LP, Piao HR. Synthesis of new chalcone derivatives containing a rhodanine-3-acetic acid moiety with potential anti-bacterial activity. Eur J Med Chem. 2010;45(12):5739-5743.

32. Chikhalia KH, Patel MJ, Vashi DB. Design, synthesis and evaluation of novel quinolylchalcones as antibacterial agents. ARKIVOC. 2008; 13:189-197.

33. Siddiqui ZN, Musthafa TN, Ahmad A, Khan AU. Thermal solvent-free synthesis of novel pyrazolyl chalcones and pyrazolines as potential antimicrobial agents. Bioorg Med Chem Lett. 2011;21(10):2860-2865.

\section{Publish your work in this journal}

Drug Design, Development and Therapy is an international, peerreviewed open-access journal that spans the spectrum of drug design and development through to clinical applications. Clinical outcomes, patient safety, and programs for the development and effective, safe, and sustained use of medicines are the features of the journal, which has also been accepted for indexing on PubMed Central. The manuscript management system is completely online and includes a very quick and fair peer-review system, which is all easy to use. Visit http://www.dovepress.com/testimonials.php to read real quotes from published authors.

Submit your manuscript here: http://www.dovepress.com/drug-design-development-and-therapy-journal 